\title{
Research on Teaching Reform of Robot Technology under the Background of New Engineering
}

\author{
Xingzhi Xu \\ College of Mechanical and Control Engineering, Guilin University of Technology, Guilin, China \\ Email: 414246895@qq.com
}

How to cite this paper: Xu, X.Z. (2020) Research on Teaching Reform of Robot Technology under the Background of New Engineering. Open Access Library Journal, 7: e7005.

https://doi.org/10.4236/oalib.1107005

Received: November 16, 2020

Accepted: December 25, 2020

Published: December 28, 2020

Copyright $\odot 2020$ by author(s) and Open Access Library Inc.

This work is licensed under the Creative Commons Attribution International License (CC BY 4.0).

http://creativecommons.org/licenses/by/4.0/

\section{(c) (i) Open Access}

\begin{abstract}
To improve the training scheme of new engineering talents, a teaching reform method on training innovation-oriented talent in robot engineering is explored comprehensively. By making a deep analysis between the graduates trained by the current robotic technology courses in universities and the talents required for the construction of emerging engineering into consideration, a teaching reform strategy of "characteristic theory teaching, practical engineering teaching, diversified assessment" has been put forward in the paper.
\end{abstract}

\section{Subject Areas}

Mechanical Engineering

Keywords

New Engineering, Robot Technology, Teaching Reform

\section{Introduction}

In order to cope with the new round of scientific and technological revolution and industrial transformation, the Ministry of Education proposed the construction plan of "new engineering" on the basis of "Outstanding Engineer Education and Training Plan" from the perspective of serving the national strategy, meeting the industrial demand and facing the future development [1] [2]. Robotics technology is an important indicator to measure the level of modern science and technology and high-end manufacturing in a country. The United States, Europe, Japan, The Republic of Korea, China and other countries have listed intelligent robots as an important industry in national development planning. "Made 
in China 2025" clearly regards intelligent robots as one of the important research fields to build a manufacturing power. Subsequently, artificial intelligence, big data, Internet of things and other "new engineering" professionals closely related to robotics are urgently needed in today's society.

Compared with the traditional teaching form in the past, the construction of "new engineering" pays more attention to the improvement of students' innovative consciousness and practical ability. The implementation of this plan provides opportunities for the development of characteristic disciplines in the "new engineering" industry, and poses new challenges to new engineering courses in colleges and universities. Generally speaking, the construction of "new engineering" requires the following characteristics for the talent training mode: 1) "New engineering" covers the new fields of science and technology that have emerged in recent years. In order to adapt to the current situation of the rapidly changing field and the rapid technological development, curriculum knowledge must be timely followed up and updated. According to their own interests and expertise, students can be trained into talents suitable for different positions to build a complete professional system; 2) "Practice is the only criterion to test truth", knowledge and technology in engineering field must be combined with practice effectively. In order to enable students to quickly become competent for the job requirements after entering the society, the teaching process must pay attention to the cultivation of students' practical ability and improve their operational ability; 3) "New engineering" is characterized by complex discipline composition and wide range of fields involved. In the process of talent training, it is necessary to break the old classification of disciplines, master the complex knowledge system structure, and complete the basic knowledge reorganization of new fields. To adapt to the new needs of science and technology and industry in the new era, students' innovation ability is cultivated, and effectively serves the talent strategic needs.

Under the background of the construction of "new engineering", this paper makes an in-depth analysis of the teaching situation and problems of undergraduate courses in the field of robotics. Combined with the "results-oriented" teaching mode, it achieves a comprehensive breakthrough in the existing talent training mode, so as to complete the reform of the traditional teaching mode, and facilitate the construction of "new engineering".

\section{Analysis of Current Situation of Course Teaching}

As a comprehensive professional course, robot technology cannot be simply taught as a general course, because it covers many subjects such as electronics, machinery and computer [3]. At the same time, the course of robot technology involves a wide range of content, such as sensor technology, single chip microcomputer technology, motor technology, software programming technology and so on.

At present, some colleges and universities mainly adopt the way of teachers' teaching in the course of robot technology, and the proportion of practice period 
in the teaching of the whole course is relatively low. This course requires students to master a wide range of theoretical knowledge, and the content has a certain depth and breadth. If the teaching of this course is purely from the perspective of teaching theory, students generally find it difficult to understand; Teachers also get poor results when they teach courses. It is necessary to make a scientific and reasonable plan from the perspective of both teachers and students when making teaching plans. On the one hand, teachers should complete the teaching tasks of this course with both quality and quantity guaranteed to achieve the established teaching objectives and effects; at the same time, students can also improve their ability of hardware and software development and design from this course.

Robot technology can not only stay at the theoretical level, but more importantly, students should be able to fully understand the working principle of robots and be able to program to control the movement of robots through the study of theoretical knowledge [4]. For some students who are interested and have a good foundation, teachers can guide students to make robot samples by themselves on the basis of existing practical robots in their spare time, which is of great benefit to improve the teaching effect and students' learning interest and ability.

\section{Content of Courses}

Under the background of new engineering, combining with the demand analysis, talent cultivation goal has not only the professional knowledge and skills of modern robot installation, debugging and maintenance aspects, but also knowledge of robot technology foundation, and has extensive knowledge at the same time, and has better practical application ability and innovation ability of the industrial robot. Finally, these applied talents can skillfully apply the knowledge of robots to the planning, design, evaluation and innovative application of the production system. The textbook selected for this course is "Robot Technology and Application" published by Machine Industry Press. The textbook is mainly divided into two parts, the first part is the basic knowledge and introduces the application technology of industrial robot; the second part is programming operation. This book is characterized by a combination of theory and practice as well as comprehensive content. This course focuses on engineering applications and focuses on the systematicness and completeness of project training to enhance students' practical ability in the teaching process. The teaching content is shown in Table 1. In order to understand the cutting-edge knowledge of the robot industry and expand the knowledge of students, on the basis of the textbook, we will pay close attention to the technical trends of various industrial robots and the relevant content of various robot competitions, so as to enrich the knowledge of this course. By improving the curriculum interest and grasp the core quality of new engineering talents, so as to promote the all-round development of students [5]. 
Table 1. Content of courses.

\begin{tabular}{ccc}
\hline \multirow{2}{*}{ number } & \multicolumn{1}{c}{ content of courses } \\
\cline { 2 - 3 } 1 & basic knowledge of robot & practice teaching \\
\hline 2 & specific professional knowledge & Introduction to Hardware and software \\
3 & personalized special system knowledge & curriculum design \\
\hline
\end{tabular}

\section{Teaching Method and Means}

The teaching of traditional robotics courses is usually carried out in the way of classroom teaching. With the rapid development of computer and network technology, teachers can also carry out teaching and tutoring activities of robot technology through network. For example, the teaching website of robot technology course will be established, and the teaching outline, teaching plan, courseware, exercises and answers, teaching items and other electronic materials of this course will be posted online for students to learn after class, so as to improve their autonomy in learning.

In addition, teachers can also invite experts and scholars related to robot research to hold lectures on robot development and design in the school, so as to improve students' scientific research quality and professional knowledge. At the same time, teachers can also hold robot competitions in the school regularly, so that students can test their theoretical knowledge through the competition, which is also conducive to improving students' practical ability.

The course of robot technology is professional, and the teaching content is difficult and abstract [6]. Students generally feel difficult to learn at the beginning of learning, so they may feel tired of learning. Teachers can consider the combination of classroom teaching and Internet teaching. On the one hand, teachers can explain professional theoretical knowledge, and on the other hand, they can learn some more abstract theories that difficult to be interpreted by textbooks through the Internet. For example, when a wheeled robot turns through a $135^{\circ}$ turn, the rotation Angle of the left and right wheels of the robot is usually planned through mathematical calculation in the textbook, then the previous mathematical calculation is programmed by software to control the operation of the robot steering gear. The same principle can be applied to the robot to make the same turn by using the photoelectric sensor or gray sensor on the network. This not only reduces the requirements for students to master complex mathematical theories, but also makes it relatively easier to achieve the goals.

\section{Practice Link}

In the aspect of practical teaching, the college adopts the way of integrating simulation software and physical workstation. The existing robot body, control cabinet, PLC, industrial computer, sensor and so on are placed in the established position, and students can choose the corresponding module for integration according to the design of the foreword.

Students first design the robot workstation according to the products and re- 
quirements provided by the teacher, and then import the mathematical model of mechanical equipment and robot into the simulation software. Then, students do their own layout design, and plan the path and form the code, and export the offline code. In this link, students need to generate production process video for assessment and follow-up work.

Students will be divided into groups. Each group will be divided into simulation engineers, mechanical engineers, electrical engineers and robot debugging engineers, etc. Each group will complete their own work and complete the integration of equipment collectively. Finally, the robot workstation can be integrated to complete the assigned tasks. Figure 1 shows the robot assembly operation training table. "Practice goes deeper than theoretic knowledge". Through the practice link, the student can realize the application of the knowledge and grasp the importance of the firm, in the practice process, also can realize the importance of safety [7].

\section{Assessment Method}

Robot technology is a course that pays attention to operation and hands-on, so we can't only regard the examination as the only standard for scoring. The construction of robot course assessment mode will improve the process assessment in the course, and combine the evaluation system with the result assessment organically [8]. The proportion of class response, class performance, homework evaluation and report should be increased accordingly, and the proportion of process score should be increased. Practice is an important part of the course construction of industrial robot technology. Therefore, in the process of practice, it is necessary to improve the requirements of students' practical ability, increase the proportion of practical examination, and highlight the importance of industrial robot course practice. Finally, we should pay attention to the examination discipline and strengthen the examination management [9].

Principles of the reform of process management and performance management assessment methods: 1) Students are forced to make use of more extracurricular time to preview and think, to build a preliminary knowledge system in advance, and then to improve the preview effect through experiments; 2) Students are encouraged to think actively and communicate with each other. All classes after normal experimental class are open to students. Teachers and experimenter guide experiments in class. 3) Through experimental practice and question-answering, classroom quiz and homework, final examination, final robot production assessment and competition, students' self-learning effect is couple back, while the openness of the assessment content is ensured.

In short, combined with the characteristics of the national robot field under the current industrial background in China, and the training goal of "application-oriented" undergraduate in our university, the key to the construction of robot course is not only to let students fully learn the theoretical knowledge of robots in the classroom, but also to attach importance to the practicality of robot. The assessment contents are shown in Table 2. Students can get out of the 


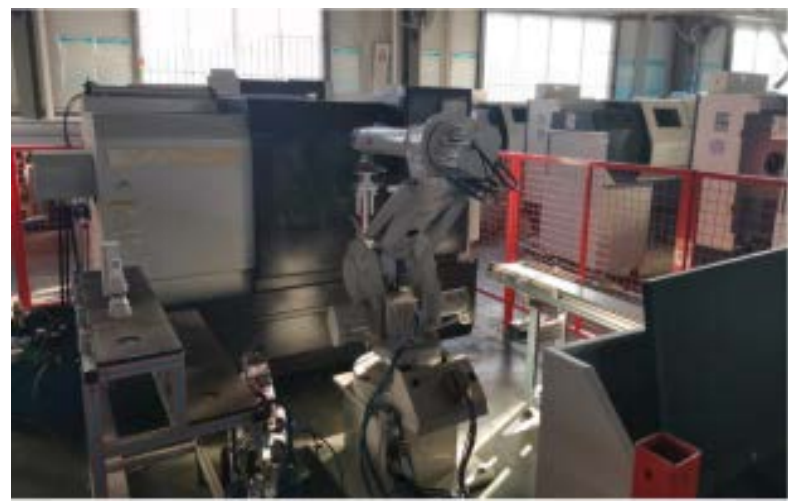

Figure 1. Robot assembly operation training platform.

Table 2. The inspection type.

\begin{tabular}{ccc}
\hline & \multicolumn{2}{c}{ the inspection type } \\
\cline { 2 - 3 } number & assessment content & field inspection \\
\cline { 2 - 3 } 2 & attendance & Protel design \\
3 & homework & motor Speed Regulation Practice \\
4 & class discussion & Simple tracking car \\
5 & pral question and answer exchange in class & industrial robot programming \\
\end{tabular}

classroom and come to work to complete the relevant work in the field of robotics, so as to improve the quality of talent training in the field of robotics.

\section{Conclusion}

The college training of robot talents required by new engineering can not only solve current problems through professional knowledge, but also have strong professional learning ability, good innovation consciousness, good social, economic and human literacy, and be able to deal with future situations flexibly. The author carries on the reform from the teaching content, the teaching method and the practice, close to the needs, to improve the industrial robot personnel training mode and the application of curriculum system. In the future, we will continue to implement new engineering concepts and strive to cultivate innovative and outstanding engineering talents.

\section{Conflicts of Interest}

The author declares no conflicts of interest regarding the publication of this paper.

\section{References}

[1] Wang, G., Ye, W.S. and Liu, N. (2018) Discussion on Knowledge Construction and Training Methods of Practical Talents in Robot Industry under the Background of "New Engineering”. Mechanical \& Electrical Engineering Technology, 8, 25-30. 
[2] Cai, X.P. and Sun, C.Y. (2017) Construction of Quality Assurance Mechanism for Application-Oriented Undergraduate Talent Cultivation under the Background of New Engineering. Journal of Yancheng Institute of Technology, 30, 71-73.

[3] Chen, T. (2018) A Review of the Development and Application of Industrial Robot Technology. Internal Combustion Engine and Parts, 1, 193-194.

[4] Cao, Y. and Sun, S.L. (2019) Reform and Exploration of the Course System of Applied Undergraduate Robotics Engineering Major. Journal of Higher Education, 12, 41-43.

[5] Zhang, W.X. and Xu, K. (2019) Research and Practice on the Teaching Reform of Robotics Course. Journal of Anhui University of Technology, 36, 68-69.

[6] Guo, L.J. (2018) Upgrading and Transformation of Electromechanical Professional Training Room under the Background of Intelligent Manufacturing. Experimental Technology and Management, 9, 158-161.

[7] Wei, X.F., Zhang, G. and He, R. (2018) Exploration on the Construction of Robot College in West Anhui University under the Background of New Engineering. Journal of Kaifeng Institute of Education, 2, 124-125.

[8] Yu, C.H. (2017) Exploration on the Teaching Reform of Industrial Robot Technology. Technology Wind, 8, 54.

[9] Zheng, H.X. (2018) Analysis of Mechanical Structure Design Methods in Current Industrial Robot Applications. South Agricultural Machinery, 16, 43. 